IJ§ER

ISSN: $2149-5939$
International Journal of Social Sciences and Education Research

Online, http://dergipark.gov.tr/ijsser

Volume: 2(3), 2016

\title{
Repetition and everydayness
}

\author{
Mustafa Cihan Camc1 ${ }^{1}$
}

Received Date: $29 / 10 / 2015$

Accepted Date: 05 / 03 / 2016

\begin{abstract}
In this paper, I will point to the temporality of the everydayness in Zbigniew Rybcynski's Tango in comparison to Heideggerian notion of temporality and handiness. Firstly, I will discuss the Heideggerian subjectivity as agency and show that subjectivity for the philosophy of life is in a temporal mood of intentionality, Sichbewegen as Heidegger says. I will point to the temporal functionality of objects as tools through which their extentional existence is negated and respond to our goal directedness as handy equipment. The availability of the handy tools is nothing but a temporal span in which objects are no longer meaningful for us as isolated extant beings but parts of an undifferentiated functional totality. The handy tools are available for us as parts of handiness in this temporal functionality. Heidegger sees this functionality as a possibility of proximity with the original temporality as a special coming to presence in repetition and says that, in repetition the meaning of life as a whole call for our awareness.

Subsequently, I will discuss the Tango characters in relation to the Heideggerian understanding of everydayness and repetition. I will state that in Tango, the inhabitants of the room are absolutely disentangled and ignorant of one other despite their apparent closeness. Even though they spatially share the small room, all the characters act as if the others do not exist. Tango characters are stuck in the repetition of the same moment and cannot let the temporalization of life flow in its spontaneity. I will refer to the Heideggerian understanding of the moment of vision in repetition out of which the meaning of life as a whole outstands and conclude that, unlike the Heideggerian interpretation of repetition, Tango characters remain in a Sisyphosian vein.
\end{abstract}

Keywords: Everydayness; Temporality; Heidegger; Repetition

\section{Introduction}

In this paper, I will point to the temporality of everydayness in Zbigniew Rybcynski's Tango, an eight minutes animation of a Polish director. Tango is a short animation basically on absurd activities of thirty-six irrelevant people in a room accompanied by an overriding tango rhythm. We start watching the film with the view of an empty room that will be gradually filled up with activities of different people that are repeated monotonously and mechanically with every episode new people and actions added up to a certain extent. Then activities lessen smoothly and come to an end. From the beginning till the end the music-tango- dominates the activities taking place in the room. The music, repeating itself relentlessly in the same tone, goes along with the irrelevant actions and somehow makes them seem alike although none of the persons or couples is related to each other. The inhabitants of the room are so disentangled that despite the apparent closeness within the small space they come together, they are absolutely ignorant and unaware of one other, never talk and converse.

\footnotetext{
${ }^{1}$ Assoc. Prof., Akdeniz University, Faculty of Letters, Department of Philosophy, cihanc@akdeniz.edu.tr
} 
On the surface, the movie seems to represent a typical modern alienation. All animated characters are busy with their own purposes and fulfill their tasks in a robotic automaticity and adjustment. They show no sign of human intimacy even when they eat, play, take care of their babies, steal and have sex. The repetition of the music emphasizes the estrangement and the boredom of the routine.

I will argue that, the repetition and the estrangement owing to the sameness of the everyday activities, somehow, lead one to consider the meaning of life as a whole. I will refer to the temporal structure of everydayness and claim that the formal structure of our daily life outstands as if it is nothing but the repetition of the same moment. I will conclude that, the meaning of life appears in that particular moment and yet still remains concealed in this appearance like Heidegger says.

\section{Subjectivity as agency}

To discuss the meaning of life as a whole, one should apprehend the living subjectivity as opposed to the Cartesian subjectivity. Living subjectivity can be characterized as agency or activity. Subject as agent, is comported towards her practical goals. The meaning of life as a whole is nothing but this directedness of the living subjectivity. We come to understand the meaning of life in and by living the life in accordance with our everyday directedness towards our needs. Subject as agent means, subject who care her needs. Agency means, being in motion to achieve one's needs. This is what Heidegger calls, being-in-the-world. "Being in the world is essentially care (BT, 193)." Dasein which is the Heideggerian name for caring subjectivity as agency. Care is the everyday mode of intentionality. Subjectivity as agency, which means human being who cares her goals, is intentional in her everyday life.

Intentionality means, being in motion towards understanding the object. Dasein comports herself to objects is in a process of understanding. Dasein, contrary to the Cartesian subjectivity that somehow survives through Husserls' notion of intentionality, does not understand the objects theoretically. Things are not subject matters but tools, Zeug, for her. "We shall call those entities which we encounter in concern 'equipment' (BT, 68). Similar to the Wittgensteinian approach to the words which views words as equipment for understanding the language practically, Dasein understands things as tools in order to make use of them for her daily goals. In this sense, understanding a thing means understanding things equipmentally. In this sense understanding means, not understanding as a cognitive achievement, Verständnis, but understanding as an act, Verstehen which means "a specific type of comportment" (BPP, 275). This is an indirect way of understanding objects. It is a vague, tacit, know-how understanding which means understanding the function of the object rather than the object itself while we are going through our everyday goals. That is a kind of understanding something in order to use that is already available, ready for our dealing with it.

I live in the understanding of writing, lighting things up, walking in and out and the like. More precisely, I am -as Dasein- speaking, walking, understanding, intelligible dealings. (Umgang). My being in the world is nothing other than this being-in-motion (Sichbewegen) that already understands in these modes of being (HPK, 118).

This being in motion as the mode of understanding daily aims is also a possibility of transcending the know-how understanding of the everyday life and understanding the meaning of being in an ontological sense. This ontological meaning is nothing but a structural whole of the 
things where they take place in a non-spatial way. “... our aim is to grasp this structural whole ontologically" (BT, 191). The meaning of being is a totality, a transcend unity of the extant beings, which is beyond their particular extensional existence, since Parmenides who sought throughout the history of philosophy. The meaning of being as such is the whatness of beings as a whole which transcends the scientific understanding of the extant things. Heidegger defines this hermeneutic possibility as transcendence. “...the understanding of being runs into something that transcends being, a 'beyond' (BPP, 286).

Nevertheless; subjectivity as agency means a restriction of understanding. We do not understand the whatness of beings as a whole as if it is standing over against us like a table, or a tree. We understand things and events in and by our modes of being. That is how we live. We understand things as parts of this howness in their functionality to serve us and the transcendence into which our understanding runs into is the whatness of this howness which is nothing but the temporalization of the original temporality as an undifferentiated flow. We will come to this point later. Firstly we should discuss the temporal character of our howness.

The howness of the everyday activities, which Heidegger calls "the ontic level of the average understanding" is temporal. Howness is nothing but activity as time consuming intendedness. Our actions take time. That is to say, they take place, exist in a temporal duration. When we care our actions, we tacitly care this temporal duration as a span. We comport ourselves to temporality in order to achieve our aims which are also temporal. So the directionality, in order to'ness, um-zu, of our temporal comportment is towards a temporal duration. Objects, to which we comport for our practical aims, also have a directional-temporal constitution for our service. It is their availability for us. We understand objects before we understand their extensional existence since we care how the objects are available for us. We have an average, vague understanding of the objects as usable tools. Their usability somehow blurs their clear cut distinction from one another as three dimensional, extant objects. Their functionality let them seem to us as internally transitive, as if they function without spatial limits.

\section{Temporal structure of intentionality and functionality}

We comport to the directionality, the, that for which, Woraufhin, of an object. Our in order to'ness, which is a temporal comportment, meets that for which of an object that is also like a temporal offer of an object for use. The restriction of the everyday understanding can be transcended by this meeting. The togetherness of the directionality of things and our practical goaldirectedness depends on the temporal structure of the howness of everydayness. The meaning of being in an ontological sense, the whatness of beings as a whole, can be understood in this temporal structure as togetherness. Let us look at this temporal offer of objects as tools more closely.

The objects in their "that for which" are not understood as extant objects, as Vorhandene but as ready to hand, handy, Zuhandene. Our interest, let us assume, is having a dinner with the friends. This is an activity in which plates, forks, the table, the food, the wine and many other objects take place and function properly together. None of these objects attract our attention as isolated objects. We do not care the plates, the food or the table as three dimensional, extant objects standing over against us. The plate, the food, the table offer themselves to us, in their serviceability. Their serviceability, as that for which, render them equipment. The equipment is not an isolated item. It is within a contexture with other items. Heidegger calls this togetherness Zeug-Zusammenhang. Although we encounter a single piece of equipment, this plate for instance, 
it is determined in each instance by the totality of the activity, having dinner with friends. The dinner is a functional totality. It is a togetherness of the function of the equipment. The plate we care is not really a plate in an extensional sense. Its particular existence as an extant object is subordinated to the functional totality of many items. When the plate is handy, Zuhandene, it is not an extant object, Vorhandene.

\section{Temporal proximity of Zuhandene and the ontological meaning of being}

A plate as Vorhandene is isolated spatially from other objects since its existence is limited due to spatial dimensionality. A plate as an extant thing stands next to the fork for example. No matter how close they stand to each other, there is always a spatial distance between their extensional beings. They take their stand together in a room but their relation is spatially determined. The limit between an object and another is determined by an extensional difference. Therefore, the fork, the plate, the table and the food remain different to each other extensionally.

On the other hand, the equipmental character of the plate, the fork, the table and the food is not limited to spatial differences. A table as equipment is that for which for us. It stands not individually but in a whole with other equipment which are also that for which for us. The table, the plate, the fork are not individual items for us but parts of a functional totality of the that for which structure. In this holistic functionality, they are indifferent to each other. The plate, the fork, the food and the table stand together as if they have never dispensed from each other. They are close in a different sense. In this proximity, their spatial limits are no longer determinative for our understanding. The things as ready to our hands, Zuhandene, are open to each other since we, in our in order to'ness, overlook the extensional limits of objects but care them as functional parts of a functional totality. The equipmental character of the beings as handy and the ontological disposition of the handy as self-opening constitute an ontological togetherness as Zuhandene:

The being most nearly encountered, that with which we have to do has the ontological constitution of equipment. This entity is not merely extant but in conformity with its equipmental character, belongs to an equipmental contexture within which it has its specific equipmental function, which primarily constitutes its, being. Equipment, taken in this ontological sense, is not only equipment for writing and sewing; it includes everything we make use of domestically or in public life. In this broad ontological sense, bridges, streets, street lamps are also items of equipment. We call the whole of all these beings handy, das Zuhandene (BPP, 292).

\section{Expectation, letting function and the presence of the handiness}

Dasein, in her everyday mood of goal directedness is usually expecting a future to come. She is futural, zukünftig. She is always projecting her goals which will take place in the future. She does not expect a fork, a table or the food as isolated objects. She disregards the objects and expects having a dinner. Her ignorance is a kind of negation of the objects as Vorhandene. Expectation, Gewärtigen, makes one comport to the objects as if they do not exist individually but has a special kind of presence as functional parts of an activity, for instance having a dinner. Before the dinner time, we are in a mood of expecting it to have a presence, Gegenwärtig. When we are expecting a dinner to come, we are expecting the ontological togetherness of the equipmental context to come. In this expectation, we are not active but just let the equipmental context 
Camc1, M.C. (2016). Repetition and everydayness. International Journal of Social Sciences and Education Research, 2 (3), 695-702.

function, that is let the dinner time be present for us. This is what Heidegger calls, letting function, Bewendlassen.

Letting function as understanding of functionality has a temporal constitution. But it itself points back to a still more original temporality. Only when we have apprehended the more original temporalizing are we able to survey in what way the understanding of the being of beings - here either of the equipmental character and handiness, Zuhandenheit, of handy equipment or of the thing-hood of the extant things and the at-handiness of the at hand, Zuhandene - is made possible by time and thus become transparent (BBP, 294).

Functionality of the equipmental context can affect us when we let it be, let it function. Letting function Bewendlassen, is what we project pre-phenomenologically while we are expecting an activity and tacitly understanding how this activity will be present. When we expect the table, the fork and the food function as handy equipment so as to have the dinner, we already tacitly understand and expect the handiness of the handy as a functional totality. In order to expect the equipment to function in accordance with our goal, we must have accepted the totality of functionality's special kind of presence that is prior to our commerce with things as handy. In other words, we accept the presence of the handiness of the handy before we use what is already ready to our hand. When we let the handy things function in our "comfortableness of the accustomed" (BT, 371), we also let the handiness of the handy come to presence. Since "the handiness of the handy is made possible by time", we let the handiness come to presence as the temporalization of temporality as self-presencing. We will come to see that, Tango characters recall a tendency to step over the everyday life in their carelessness but remain restricted in the repetition of the same moment. Tango characters, in their floating attitudes seem to ignore the other people and other objects in the room and surpass the functionality of the equipment; nevertheless, they cannot let the temporality as the totality of functionality relations come to presence but are stuck in the static presence of the moment. The reason why the Tango characters cannot let the temporality of the totality of functional relations come to presence is their being wedged at the same now. They cannot let their time that is to do something, flow in to the undifferentiated flow of the original temporality. Their time, which is their understanding as being in motion, does not pass into the original continuity of time. Their time, which is a span, remain detached from the time as such. Their time cannot become an undifferentiated span of the original time. In order to see how our time is undifferentiated from the original time, we need to look at the double bindedness of the presentness of time for Heidegger as a transition from absence to presence.

\section{Temporalization of temporality, the double bindedness of the presence of functional to- tality}

Temporalization of temporality is the pre-phenomenological condition of the letting function Bewendlassen. In order to be able to expect the equipment to function in accordance with our goal, we must have accepted the totality of functionality's special kind of presence that is prior to our commerce with things as handy. In other words, we accept the presence of the handiness of the handy before we use what is already ready to our hand. Time is the horizon of the notion of before. Thus, the pre-bias presence of the handiness is the self-presencing of the temporalization of temporality as we have mentioned above. This presence, since tempoalization can only be considered as an ecstatic transition, is a while of the togetherness of presence and absence, prae- 
sens. Letting function is letting the temporalization of temporality as self-presencing in a transitory existence. Since time is constituted by the succession of moments for us, this transitory presence, which is in itself a span of time, a while, is understood as a moment. That is what Heidegger calls, the moment of vision, augenblick. What happens in this moment can be summarized as follows: In my everyday concern, I comport to an object, a plate for instance. This object does not appear to me as an extensional object that is determined as a distinctive plate. This object does not appear to me as Vorhandene. Due to my practical interest, my in order to'ness, the plate appears to me as a tool, as a part of a functional totality. It appears to me as Zuhandene. In other words, I transcend the extensional limits of the plate and let it serve to my practical interest. The plate is not an extant object, Vohandene, but handy tool, Zuhandene. It is, as a part of handiness, open to me for a while as if it has no extensional limits as long as I am dealing with it, for instance, having a dinner. Having a dinner is nothing but a time consuming activity, a temporal span when one considers its whatness formally. In this context, I am letting the plate function for a while, as a span of temporality. Temporality can be understood only with reference to itself. Thus, for my taking time for having a dinner, understanding it in a vague sense, I have been already understanding and accepting the formal structure of time in advance. Taking my time for dinner, I am letting the temporality temporalize itself. In other words, I let the being be. That is to say, I am letting the being be for a while. This while, which is not the being as such since it is a restricted span of it, is yet un-differentiated from being as such. That is why it is a transitory moment of presentness between present and absent. Thereby, my time consuming activity is an undifferentiated, nicht-unterscheidet span of the functional totality.

In this spannedness, the ecstatic togetherness of being and nothing touches us for a while, during a twinkle of an eye. This is the event of the present as presencing, as Heidegger calls it, Gegenwart als Gegenwärtigen. Letting function is the passage through which we let the beings be as they are. "We let all beings be as they are" (IM, 81).

\section{Tango and the letting function}

In the movie, we see different characters dealing with their everyday interests. They look like taking their time properly in order to actualize their goals. They take their time "in a certain "whiling" or "tarrying a while". The woman has her while in taking care of the baby. A boy, playing with his ball is taking some time and a thief is taking his time while stealing things. A couple has sex for a while. The different characters never intercourse each other. They seem having their own while. Nevertheless, they are repeating the same while. All through the movie, every character seems detained at the very same activity. We feel like the time goes on; some characters enter into the scene and some go away. Yet they repeat the same activity while they exist in the movie and appear to us as if they are confined in the same span of time. They are unable to let the time to temporalize itself towards a future. All they are able to do is repeating the same moment. Their repetition makes us feel like time is always a now in which the past and present gripped and the original continuity of time is being let to temporalize itself in this repeated span. The original continuity of time is an unlimited, continual flow of self-temporalizing. On the other hand, time temporalizes itself as a now-sequence (BPP, 268) and that is how the meaning of time is accessible to us. Time as such, the whatness of time is this howness for us. So now, must be related to the meaning of time that is the howness of time and yet still project the original time. 
Camc1, M.C. (2016). Repetition and everydayness. International Journal of Social Sciences and Education

Research, 2 (3), 695-702.

\section{Now}

Now is said to be the only possible presentness of time since past is no longer and future is not yet. "... at bottom, it is only the present, the now, that is" (BPP, 233). Now is a formal stretch in which time as an original undividedness comes to presence. It is like a joint of the undivided continuity, the sameness of the original time and our divided notion of time for our everyday goals. "Time is held together within itself by the now; time's specific continuity is rooted in now" (BPP, 247).

This formal stretch is like an embodiment of now. Now itself is never the same now in a continuous flow but at the same time, it is the same what it always already was -that is in each now it is now; its essential, its what, is always the same (tauto)- and nevertheless every now is, by its nature, different in each now, to d' einai auto heteron; nowness, being-now, is always otherness, being-other (being-how or hownessexistentia-heteron). The now in a certain way is always the same, but then it is never the same (BPP, 247-248).

In our everyday mood of goal directedness, we are expecting a future to come to achieve our goal, for instance having a dinner. We are usually expecting the span of now as a near future, which is in this case the dinner time that seems us as a different span of time. We reckon the dinner time as a different while, an isolated span of time as if it is extensionally disconnected from now, the while we are experiencing as present. We reckon the dinner time as if it is standing after the coffee time like a plate standing next to the fork. However, the original dinner time is nothing but an undivided part of the original temporality. The dinner time is different from the coffee time as long as it is for us. It is how we understand it in our everydayness. The whatness of the dinner time, whatness in the sense that it is in and for itself, is un-differentiated from the original temporalization of temporality. The dinner time in itself is a reflection of the undivided presence of the original time. Thereby, it is involved in the now, "which means time" (BPP, 249).

The boy, like all the other characters in Tango, while repeatedly playing with the ball, does not let the time flow as we expect in conformity with the habitual easiness of the everydayness. He stops the daily flow. In other words, he stops motion. "If we stop motion, we say that time continues. Time goes on while the motion ceases" (BPP, 238), the boy seems to stop motion so as to sense the time in itself as if it is embodied in a purely formal presence. In the embodiment, we feel like the same now continues and the boundary between the coffee time and the dinner time is blurred. The boy suspends his expectation of the future lets the now announce itself in the repetition.

Nevertheless, he looks trapped at the suspension. Tango characters, seeming obsessively stuck in repetition, recollect the Heideggerian moment of vision. Repetition is nothing but the possibility of remembering the forgotten undividedness of the original time in the stretched now. (BPP, 242). Tango characters are not being in motion. Neither can they feel the closeness of the dance. They rather resemble a Sisyphosian struggle in their frozen now. The tools they use function smoothly; nonetheless, the absence of the objects as Vorhandene does not pass in to a presence of Zuhandene. They do not let the spontaneous flow of being as self presencing and do not expect the future where the undivided originality of temporality holds itself as an ontological oneness. 
Camc1, M.C. (2016). Repetition and everydayness. International Journal of Social Sciences and Education Research, 2 (3), 695-702.

\section{References}

BT: Heidegger, M. (1995). Being and Time. Translation, John Macquarrie and Edward Robinson, Oxford: Blackwell Publishers.

Heidegger, M. (2006). Sein und Zeit. Max Niemeyer Verlag Tubingen.

BPP: Heidegger, M. (1989). Basic Problems of Phenomenology. Translation, Albert Hofstadter, Bloomington - Indianapolis: Indiana University Press.

Heidegger, M. (1975). Die Grundprobleme der Phänomenologie. Klostermann Seminar, Vittorio Klostermann Frankfurt.

PIK: Heidegger, M. (1997). Phenomenological Interpretation of Kant's 'Critique of Pure Reason. Translation, Parvis Emad and Kenneth Mally, Bloomington - Indianapolis: Indiana University Press.

FCM: Heidegger, M. (1995). The Fundamental Concepts of Metaphysics: World-Finitude-Solitude. Translation, William McNeill and Nicholas Walker, Bloomington - Indianapolis: Indiana University Press.

IM: Heidegger, M. (2000). Introduction to Metaphysics. Translation Gregory Fried and Richard Polt, London: Yale University Press.

OHF: Heidegger, M. (1999). Ontology: Hermeneutics of Facticity. Translation, John Van Buren, Bloomington - Indianapolis: Indiana University Press.

HPK: Guignon Charles B. (1983). Heidegger and the Problem of Knowledge. Hackett Publishing Company, Indiana. 